\title{
Analysis of wind energy generation possibilities with various rotor types at disadvantageous wind condition zones
}

\author{
Andrzej Bieniek ${ }^{1, *}$ \\ ${ }^{1}$ Opole University of Technology, Faculty of Mechanical Engineering, 45-271 Opole, Poland
}

\begin{abstract}
The paper describe possibilities of energy generation using various rotor types but especially with multi-blade wind engine operates in the areas with unfavourable wind condition. The paper presents also wind energy conversion estimation results presented based on proposed solution of multi-blade wind turbine of outer diameter of $4 \mathrm{~m}$. Based on the wind distribution histogram from the disadvantage wind condition zones (city of Basel) and taking into account design and estimated operating indexes of the considered wind engine rotor an annual energy generation was estimated. Also theoretical energy generation using various types of wind turbines operates at disadvantage wind conditions zones were estimated and compared. The conducted analysis shows that introduction of multi-blade wind rotor instead of the most popular 3- blades or vertical axis rotors results of about 5\% better energy generation. Simultaneously there are energy production also at very disadvantages wind condition at wind speed lower then $4 \mathrm{~m} \cdot \mathrm{s}^{-1}$. Based on considered construction of multi-blade wind engine the rise of rotor mounting height from 10 to $30 \mathrm{~m}$ results with more then $300 \%$ better results in terms of electric energy generation.
\end{abstract}

\section{Introduction}

World demand for electricity is growing year by year. As a result, various solutions are being sought to meet these growing needs. According to some sources [1], the increase in electricity demand between 2000 and 2008 increased by $22.2 \%$ and continues to grow. Much of the demand for electricity is covered by power plants that use fossil fuels (coal, gas, oil) (Fig. 1). Total share of fossil fuels in world energy production in 2011 amounted to almost $68 \%$. The share of renewable energy in this case amounts to about $4.8 \%$, but as shown by statistics, it is growing rapidly in recent years [2].

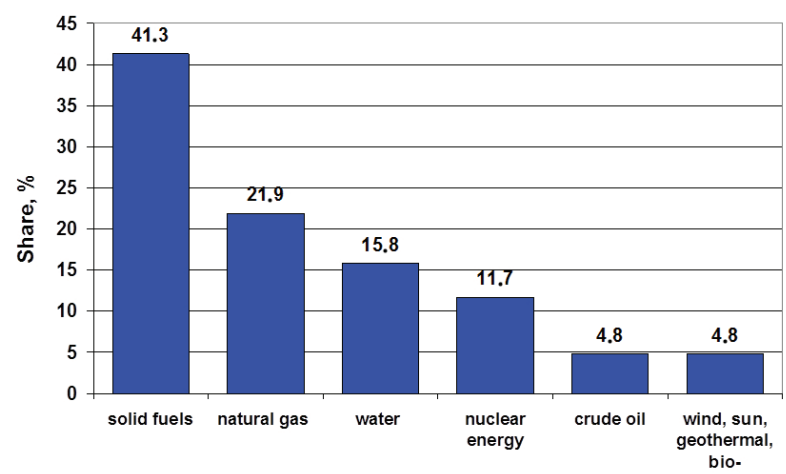

Fig. 1. Share of fuels in global energy production in 2011 [2].

Particularly there is high dynamics of energy growth produced by the use of wind energy [3]. In Europe in the recent years there is a rapid development of wind energy observed (Fig. 2). There is growing importance to produce energy mainly for own use with the use of small wind power plants. As example in one of the EUcountries in the strategic document of the National Action Plan for the Promotion of Renewable Energy Sources - small wind energy (ie. for power below 100 $\mathrm{kW}$ ) was separated for the first time as a separate category and at the same time it was stated that in Poland by 2020, $550 \mathrm{MW}$ power in this sector. This represents approximately one hundred thousand installations.

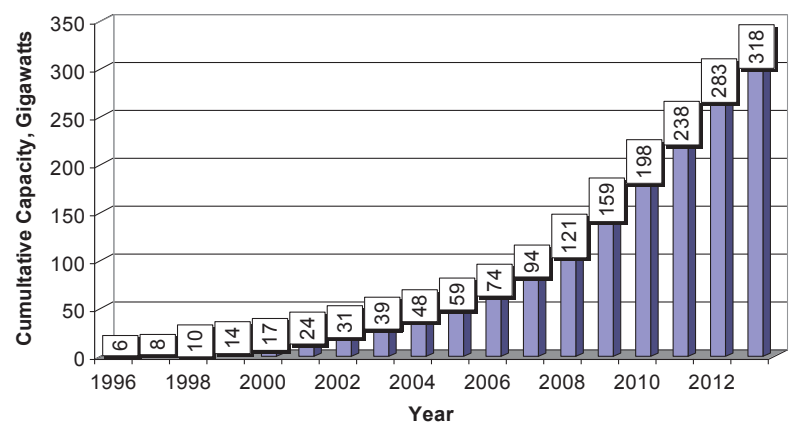

Fig. 2. Wind energy production in years from 1996 to 2013 [3].

As expected, many of these installations will be small home installations with a power of the order of 3-5 kW installed on buildings or masts up to $30 \mathrm{~m}$ high. Statistical analysis show that a small wind turbines with a total power capacity of $7 \mathrm{MW}$ was installed in Poland by the end of 2010, of which over 5.2 MW were small wind turbines producing energy for their own needs. As shown it is only about $1.5 \%$ of power capacity planed to started up to 2020 year [4]. The most sold wind turbines

\footnotetext{
* Corresponding author: a.bieniek@po.opole.pl
} 
in Poland are the smallest pico- and micro-turbines from the power range up to $5 \mathrm{~kW}$. Most of these turbines operate in autonomous systems with about 53\% with batteries or $27 \%$ of domestic heating water. The most economical version of "surplus" storage is the connection to the power grid, howewer few investors decides to do so because of technical difficulties, and possibly due to the most unfavorable legislation in this regard.

\section{Europe's wind energy potential}

Determination of wind energy resources requires a multi-year wind speed measurement. As the statistical data of many world agencies show, it is difficult to forecast wind speeds in the so at short and also on the long term future due to their high variability. On the basis of years of research and wind measurements there are wind maps developed by the European Environment Agency (EEA). It can be stated that Europe is a continent in which only favorable wind conditions exist in a relatively restricted area [5]. The relatively favorable windiness conditions can be considered in areas with an average wind speed of more than $6 \mathrm{~m} \cdot \mathrm{s}^{-1}$ (Fig. 3) measured at $80 \mathrm{~m}$ above ground level or $120 \mathrm{~m}$ above water level.

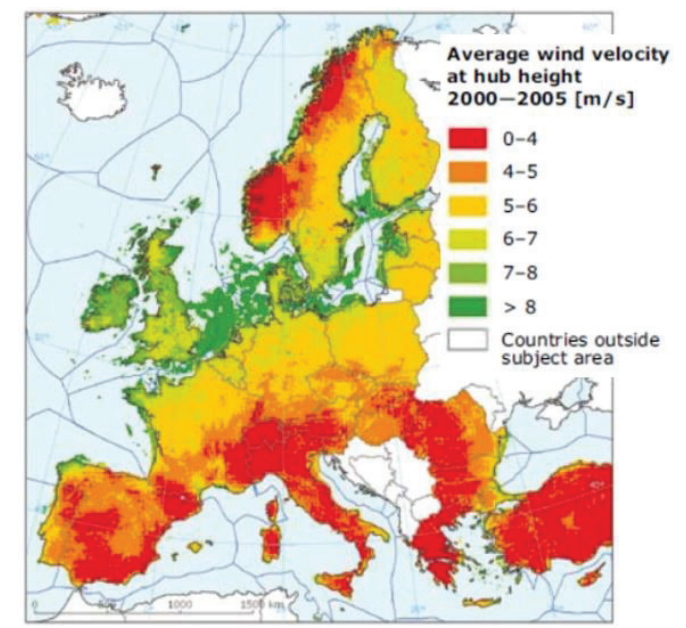

Fig. 3. Wind field data after correction (by hub height of $80 \mathrm{~m}$ onshore/ 120m offshore) [5].

Similar is also the distribution of the zones in which wind turbines placed at a height of $80 / 120 \mathrm{~m}$ above the surface can reach its maximum energy generation (Fig. 4). By analyzing the EEA, it can be seen that the most advantageous area is the northern part of Europe along the coast located, where the annual number of hours for maximum capacity reach more than 2000 hours. There are also significantly less favorable zones such as the areas of the northern part of the Scandinavian peninsula and southern Europe, where the full potential of a wind power plant is achievable for significantly less than 1000 hours a year. On the other hand, the assessment of the use of wind energy in a particular location, especially for small wind turbines installed at relatively low altitudes, should be carried out on a case-by-case basis. It is difficult to assess and predict the wind speed profile at a given area due to the lack of detailed data, especially long-term archival wind speed data.

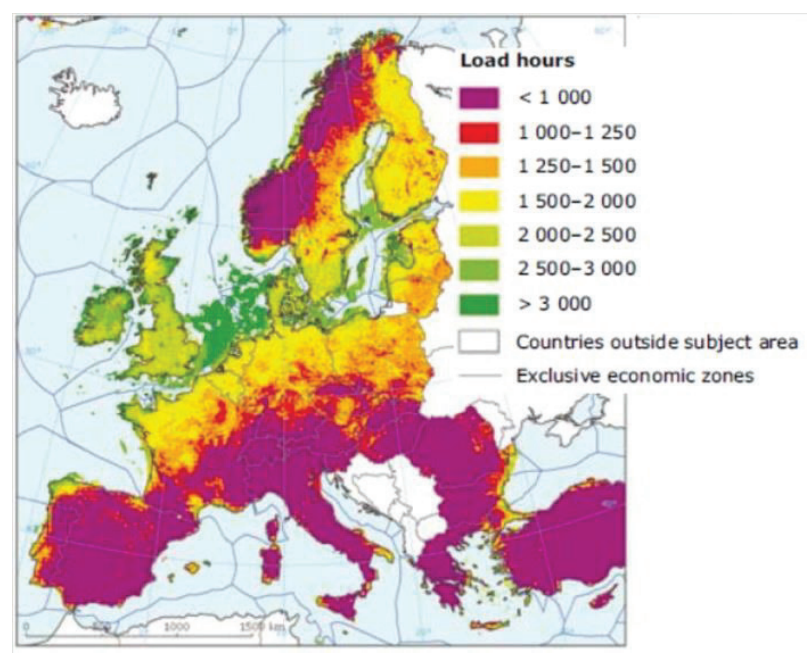

Fig. 4. Distribution of full load hours in Europe (by hub height of $80 \mathrm{~m}$ onshore/ $120 \mathrm{~m}$ offshore) [5].

In this case, the analysis of the pre-selection from several locations can use the data available to the nearest location for which the data is available. Then is possible using empirical relations to estimate the energy production capacity of a particular location.

\section{Short- and long-term windiness characteristic}

An important issue for cost-effectiveness of the investment wind turbine is a presence of the favorable windiness conditions. The average value of wind speed that determines the electric energy generation. Significant is both short-term and long-term changes in wind speed. The profile of these changes is equally important. In the case of short-term changes (turbulence and gusts), the limits (maximum and minimum) of wind velocity may vary widely. In the perspective of several days, there are also significant differences in wind speed mainly observed.

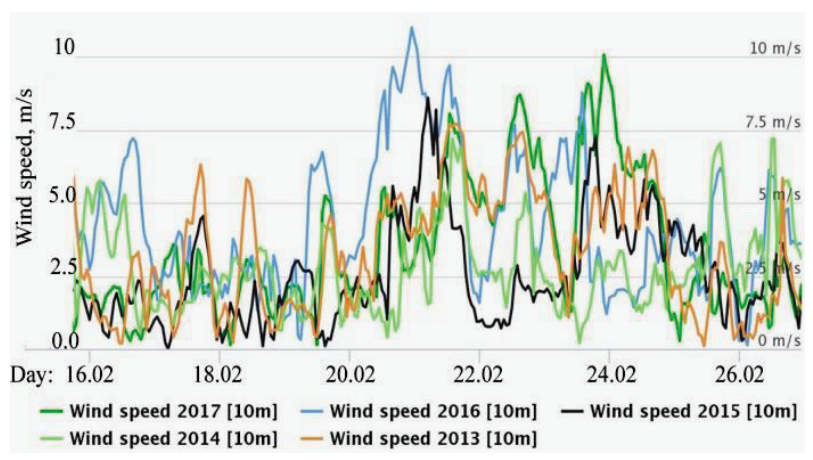

Fig. 5. Wind speed fluctuations in from 16 to 26 February over the past 5 years in Basel [6]. 
Especially in areas with less favorable wind properties, there may be longer periods when the wind speed falls below the electricity energy production limit (Fig. 5). These case can be remain even several days or longer when the wind speed falls below $4 \mathrm{~m} \cdot \mathrm{s}^{-1}$. For most of the wind turbine designs, this is a critical value below which, it is not possible to start a wind turbine rotor and energy generation.

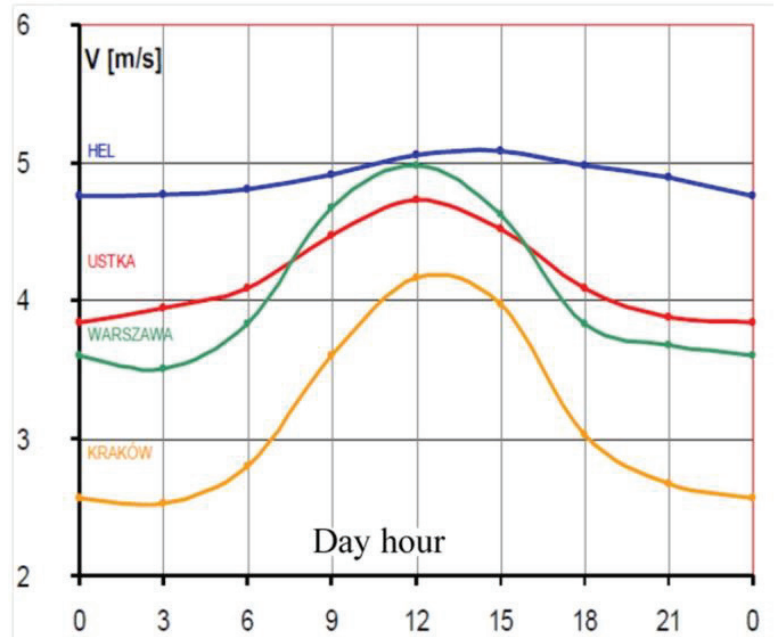

Fig. 6. Variability of wind speed in daily terms [7].

The direct use of wind energy by an individual user should also be take into account the daily wind speed distribution. In this case mainly the highest wind speeds are recorded in the afternoon hours (Fig. 6).

\section{Efficiency of wind energy conversion}

A very important feature in assessing the use of wind power is the characteristic of the efficiency of the wind energy conversion achieved by individual wind turbine rotor designs. The greatest possible theoretical efficiency of wind energy conversion by a wind turbine is described by the Betz curve, whose maximum is reached to 0.59 . In turn $[9,10]$, the total energy of the air stream (wind) can be saved by the formula:

$$
P_{\text {wind }}=0.5 \rho \mathrm{AV}
$$

were:

$$
\begin{array}{ll}
\rho & - \text { air density, }\left(1.16 \mathrm{~kg} \cdot \mathrm{m}^{-3}\right) \\
A & - \text { stream thrust area, } \mathrm{m}^{2} \\
V & - \text { wind speed, } \mathrm{m} \cdot \mathrm{s}^{-1}
\end{array}
$$

The wind energy conversion efficiency depends to a large extent on turbine rotor design, differences in the characteristics of this important feature are significant. Fig. 7 shows efficiency of wind energy conversion curves $\xi$ and the torque curves $\psi$ (at the bottom of the figure) for the various types of rotors. Rotor type II, IV and $\mathrm{V}$ achieve the highest efficiency of $0.35-0.37$ (Fig. 7) [8]. Achieving the maximum efficiency however, requires the rotor to operate optimally at the speed rating
$\mathrm{Z}$ of turbine, that determines the ratio of the peripheral speed of the outer rotor to the wind speed:

$$
Z=\frac{\omega R}{V}
$$

were:

$\omega \quad$ - rotor angular speed, $\mathrm{rad} \cdot \mathrm{s}^{-1}$

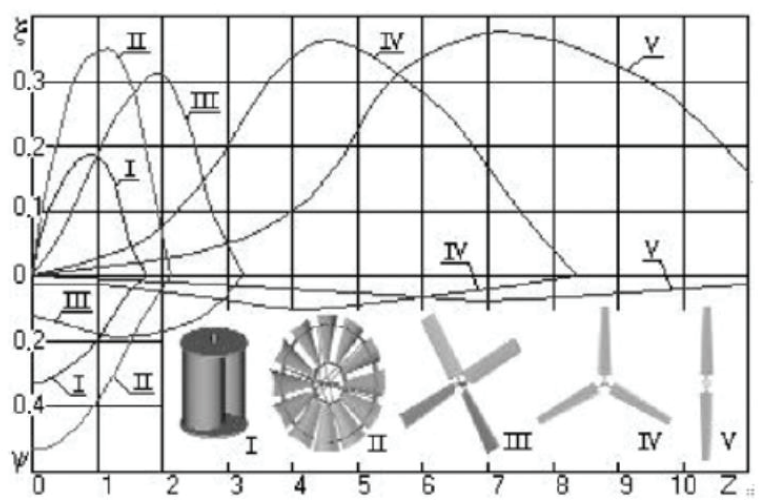

Fig. 7. Key parameters of various types of wind rotors depending of speed rating $\mathrm{Z}$ [8].

Knowing the course of the wind energy conversion curve, it is possible to record the useful power generated in a wind turbine using the following formula:

$$
P_{\text {turb }}=0.5 \rho V^{3} \pi R^{2} \xi
$$

were:

$R \quad$ - rotor radius, $\mathrm{m}$

$\xi \quad-$ wind energy conversion efficiency, -

The efficiency of wind energy conversion is dependent on many factors (including flow patterns, rotor type and structure), and its estimation is possible also in the case of wind speed measurement before and after the rotor:

$$
\xi=\frac{1}{2}\left(1-\left(\frac{V_{2}}{V_{1}}\right)^{2}\right)\left(1+\frac{V_{2}}{V_{1}}\right)
$$

were:

$$
\begin{array}{ll}
V_{1} & \text { - upstream wind speed, } \mathrm{m} \cdot \mathrm{s}^{-1} \\
V_{2} & - \text { downstream wind speed, } \mathrm{m} \cdot \mathrm{s}^{-1}
\end{array}
$$

The assessment of the various design of rotors should be also pay attention to the torque curve $\psi$, from which the course depends, among others the minimum wind speed at which rotor rotation and power generation are possible. Definitely the most advantageous course of the discussed curve is related to type II impeller, i.e. multiblade rotor. At present, in the case of low power wind turbines, three-blade rotors (type IV) are most commonly used. They are characterized by a favorable maximum wind energy conversion value but require a minimum wind speed of about $4 \mathrm{~m} \cdot \mathrm{s}^{-1}$ for their start. Experimental studies carried out by the author for the model of multiblade rotor with 24 blades rotor of of $0.2 \mathrm{~m}$ outer 
diameter showed that the starting velocity for such a construction is approx. $1.5 \mathrm{~m} \cdot \mathrm{s}^{-1}$

\section{Eco-energy generation potential with small multi-blade wind turbines}

As shown by statistics compiled by some meteorological measuring stations in the area involved unfavorable wind wind speeds exceeding $4 \mathrm{~m}^{\cdot} \mathrm{s}^{-1}$ has a small share (Fig. 8). At the same time, the wind speed is characterized by high day variability (Fig. 6), which may additionally cause downtime in the power plant due to too low wind speed. The measured mean wind speed variability for the city of Kraków lying in the disadvantageous windy zone is in the range of $2.5-4.2 \mathrm{~m} \cdot \mathrm{s}^{-1}$, whereas the daily wind share of speeds higher than $4 \mathrm{~m} \cdot \mathrm{s}^{-1}$ does not exceed $20 \%$ [7]. However, in the coastal areas in the very favorable windy zones, the daily share of winds of more than $4 \mathrm{~m} \cdot \mathrm{s}^{-1}$ can reach $100 \%$ (Baltic coast). As can be seen for many frequently used wind turbine constructions, wind speeds occurring in areas with poor wind conditions are insufficient for their operation.

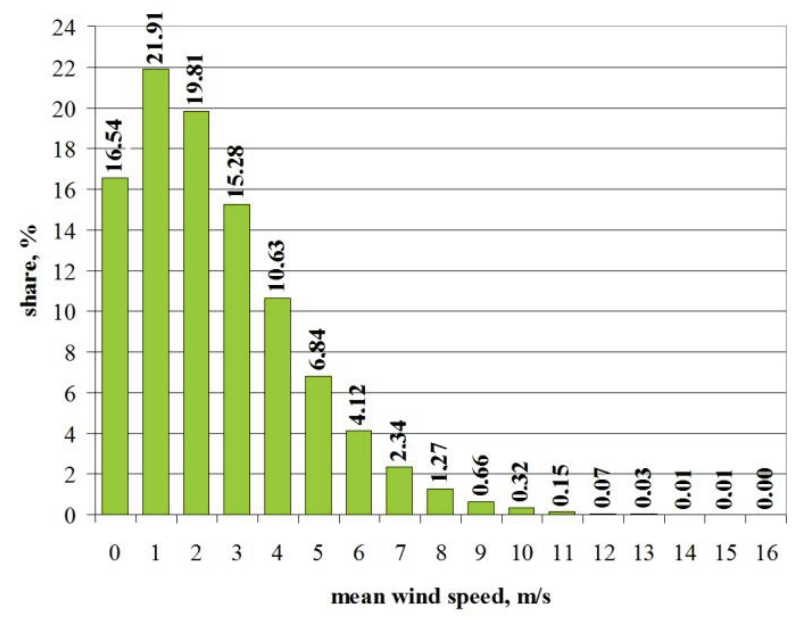

Fig. 8. Wind speed histogram for the city of Basel from 2010 to 2015 [6].

Taking into account the distribution of average wind speeds in zones with unfavorable winds conditions, the possibility of producing electricity for different types of rotors was compared. For the comparison was selected 3 types of rotor construction: a very commonly used in areas with favorable wind parameters rotor type IV, rotor type II (multilayer windmill / wind engine) and vertical rotor type I [8]. Rotors with vertical rotation axis usually have a significantly lower maximum wind energy conversion efficiency $(\xi=0.18)$. The advantage of type I and II rotors is they start and operation possibility at a relatively low wind speed of about $1.5 \mathrm{~m} \cdot \mathrm{s}^{-1}$. Considering the higher efficiency of the type II rotor vs. rotor type I and the low startup wind speed (about $1.5 \mathrm{~m}^{-1} \mathrm{~s}^{-1}$ ), further analysis was based on a small wind turbine equipped with a multi-blade rotor. The advantage of this solution is that nominal power values are also high at wind speeds of more than $10 \mathrm{~m} \cdot \mathrm{s}^{-1}$, similarly for triple blades rotor of type IV. Further analysis was carried out for a multi-blade turbine consisting of 24 blades forming a rotor with an outer diameter of $4 \mathrm{~m}$ This rotor constructions was modeled for the purpose of this analysis (Fig. 9).

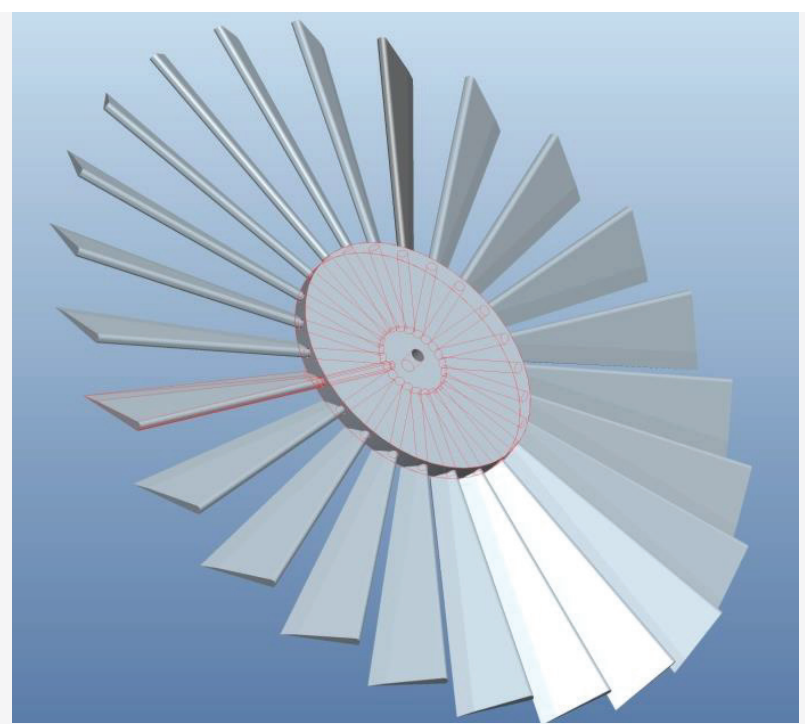

Fig. 9. 3D model of 24 blade wind engine rotor.

Based on the theoretical data $[4,9,11]$, an estimation of the energy efficiency characteristic of the rotor model was performed (Fig. 10).

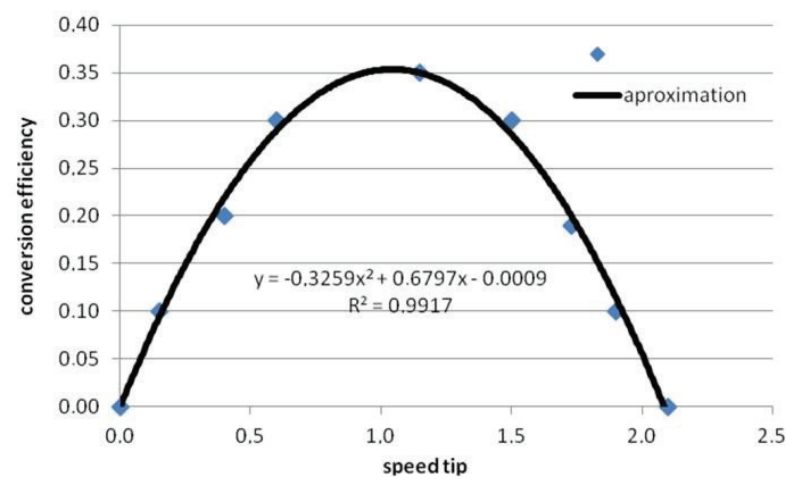

Fig. 10. Theoretical multi-blade rotor energy conversion efficiency.

Theoretical maximum efficiency of a model rotor is used $(\xi=0.35)$ for $Z=1.04$. In a large range of speed rating $Z$ from 0.9 to 1.2 , the efficiency of the turbine is almost constant (the deviation from the maximum value is not more than $2 \%$ relative to the maximum value). This facilitates obtaining the optimum turbine performance over a wide range of rotational speed of the turbine. On this basis, the maximum power of the turbine equipped with the rotor of the above design was estimated (Fig. 11).

In order to achieve the maximum efficiency of wind energy conversion, the variables for speed rating Z_tip1 $=0.9$ and $Z$ _tip2 $=1.2$ (as values for almost constant turbine efficiency) were defined as the minimum and maximum rotational speed of the rotor. For that range of speed rating (2) the wind engine with multi-blade rotor achieves maximum conversion efficiency (Fig. 12). 


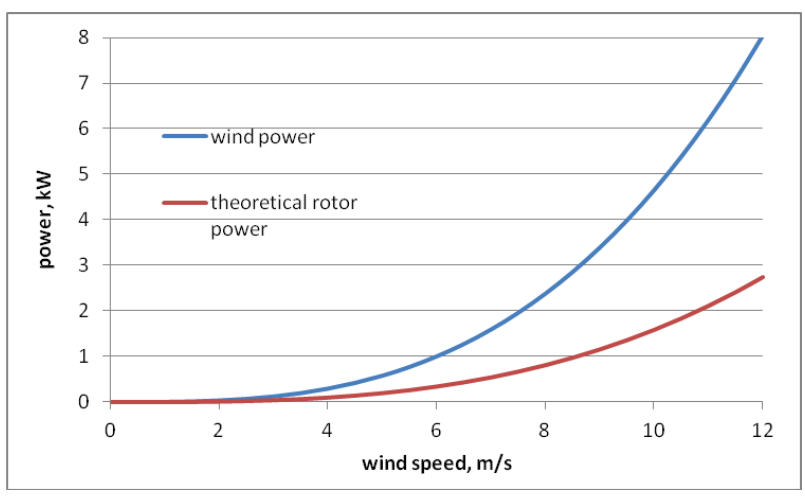

Fig. 11. Theoretical power of wind and modelled multi-blade rotor.

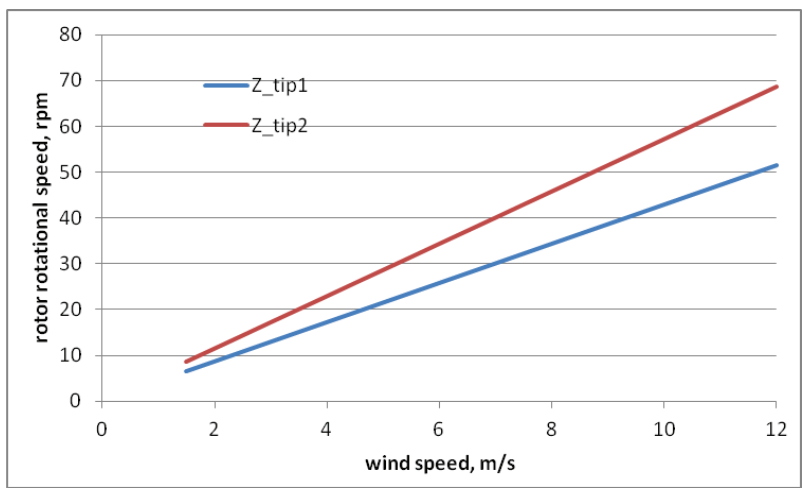

Fig. 12. Optimal rotor rotational speed vs. wind speed.

Based of the wind distribution histogram for the city of Basel (Fig. 8) and considering the construction of the modeled rotor, and in particular its estimated parameters (Fig. 10-12), the annual production was calculated with the details of its components for each wind speed, expressed in absolute terms $(\mathrm{kWh})$. The value of the electricity produced was compiled with results based on the theoretical properties of other types of rotors [8] Fig. 13.

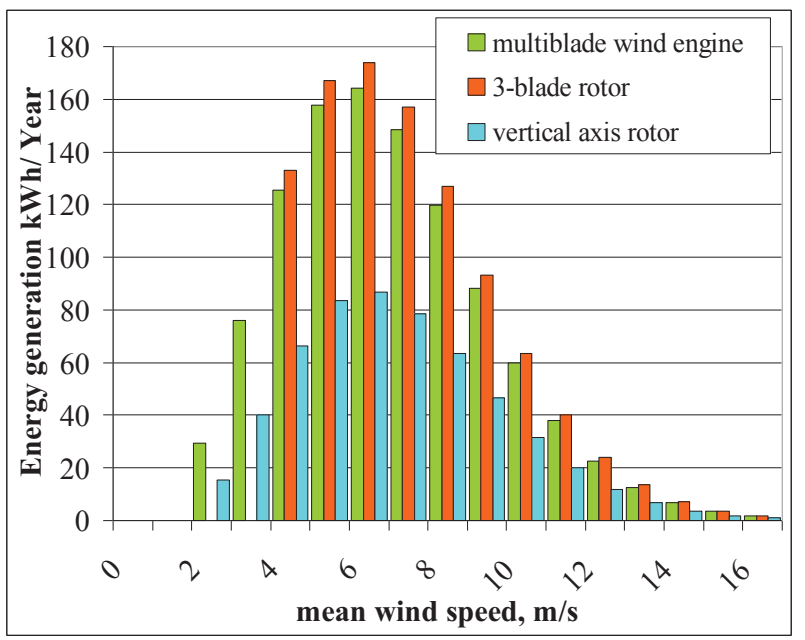

Fig. 13. Components of electricity production with various rotor types for the city of Basel located at a height of $10 \mathrm{~m}$.

The analysis of Fig. 8 and 13 shows that, despite the fact that the share of wind speed from 1 to $2 \mathrm{~m}^{-1} \mathrm{~s}^{-1}$ is about
$40 \%$, the greatest amount of energy is produced at a wind speed of 5-6 m/s. . Such applications should be taken into account in optimizing the operation of the turbine for particular wind speed ranges. Based on the distribution of wind velocity and theoretical data on the efficiency of wind energy conversion to mechanical energy, taking into account the efficiency of current generators, the possibility of producing electricity was estimated using various types of wind turbines: multiblade, 3-blade and vertical rotor.

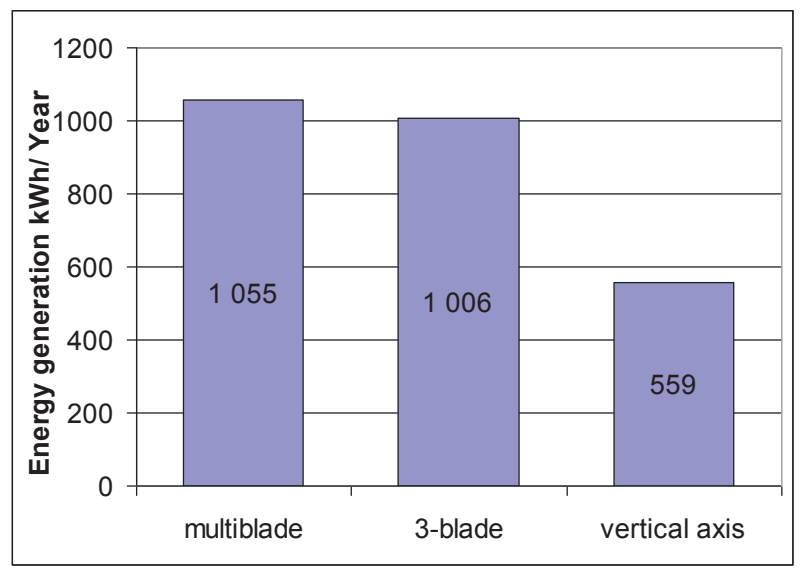

Fig. 14. Comparison of annual energy production by various rotor types.

The results are shown in Fig. 14. The use of a multiblade rotor for less favorable wind conditions gives about $5 \%$ better results in terms of energy generation and is far more effective than a vertical axis rotor.

Considering the legal status that allow use of wind turbines mounted at a height of up to $30 \mathrm{~m}$ with less number of permits required by such installations, an analysis of the impact of height turbine placement on the estimated value of annual energy production was carried out. Using formula $[9,10,12]$ :

$$
V_{h}=V_{0}\left(\frac{h}{h_{0}}\right)^{\alpha}
$$

were:

$$
\begin{aligned}
& V_{h^{-}} \text {wind speed at height } \mathrm{h}, \mathrm{m} \cdot \mathrm{s}^{-1} \\
& V_{o} \text { - wind speed at measured height, } \mathrm{m} \cdot \mathrm{s}^{-1} \\
& h \text { - reference height, } \mathrm{m} \\
& h_{o} \text { - measurement height, } \mathrm{m} \\
& \alpha \text { - terrain factor, }
\end{aligned}
$$

the wind velocity was estimated. Based of the average wind speed for Basel of $\mathrm{V}=3.337 \mathrm{~m} \cdot \mathrm{s}^{-1}$ (using Weibull formula) at the reference level of $10 \mathrm{~m}$ and also accepting terrain factor for the: undeveloped area $\alpha=$ 0.143 , built-up area $\alpha=0.27$ and the urban $\alpha=0.35$ the average wind speed for different elevations above the ground are estimated (Fig. 15) [12].

Based on the wind speed histogram for the city of Basel (Fig. 8), an estimation of wind speed was made at altitudes of $5-30 \mathrm{~m}$ and the annual total energy generation was compared with the modeled multi-blade wind turbine (Fig. 16). 


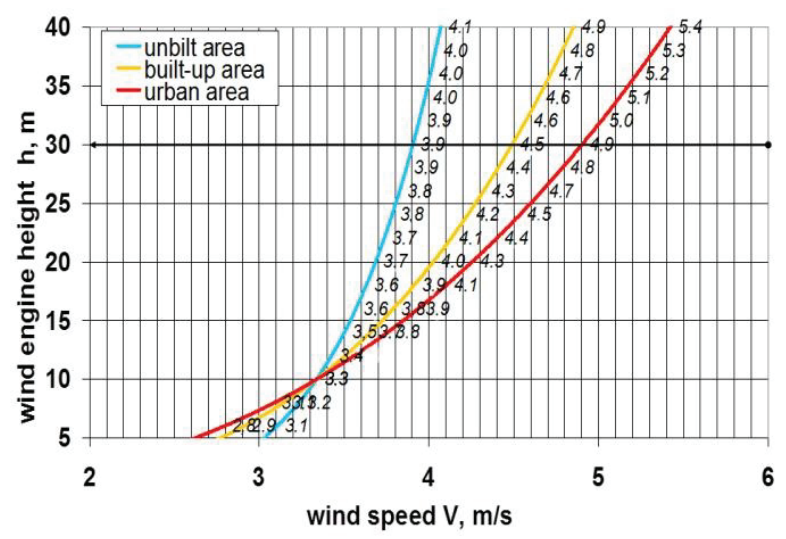

Fig. 15. Wind speed at different areas types by various rotor mounting height.

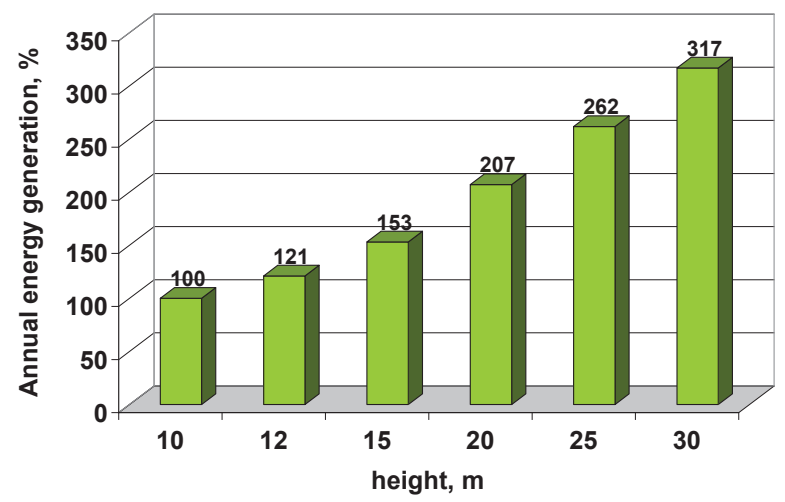

Fig. 16. Comparison of annual energy production by various height of rotor.

As the height of the rotor is increased, the amount of generated energy is increasing rapidly due to the more favorable wind parameters (speed). In this case rotor height increase from 10 to $30 \mathrm{~m}$ causes increase the energy generation of more then $300 \%$.

\section{Conclusions}

Europe is a continent with relatively more areas with disadvantages windinies condition. At this zones share of wind speed higher then $4 \mathrm{~m}^{\cdot} \mathrm{s}^{-1}$ does not exceed about $20 \%$. As shown by preliminary analyzes carried out in this studies in areas with less favorable wind conditions, it is appropriate to consider low power wind turbines with multi-blade rotor due to the startup with advantageous value of wind speed and high torque at low wind speeds. The large share of wind speed (e.g. in Basel province) below the starting speed of many popular three-blades rotors makes these turbines less profitable under such wind conditions. In turn, due to the low rotational speed of the multi-blade turbine rotor, the use of innovative low speed rotary power generators based on neodymium magnets technology should be considered. Introduction in these areas multi-blade wind engines are more profitable then other types of rotors. That results with about $5 \%$ higher energy generation then by popular 3-blades turbines and almost $90 \%$ more energy generation then vertical axes type. Simultaneously multi-blade rotors ensure more stable energy generation - even at small wind speed lower then $4 \mathrm{~m}^{-1} \mathrm{~s}^{-1}$. At the same time, besides choosing the optimum location for the turbine assembly, it is of utmost importance for the energy production effect the height of rotor location. Conducted in this paper analysis shows possibilities to increase energy generation for example of more then $300 \%$ at raising of rotor mounting height from 10 to $30 \mathrm{~m}$.

\section{References}

1. IEA, Energy Balances of Non-OECD Countries, (Eenergiläget and Siffror, 2011)

2. IEA, Keyworld energy statistics (IEA, 2013)

3. GWEC, Global Wind Report Annual Market Update (2014)

4. IEO, Rynek matych elektrowni wiatrowych $w$ Polsce (EC BREC, 2010)

5. EEA technical report 6/2009, Europea's onshore and offshore wind energy potential (EEA, Copenhagen, 2009)

6. www.meteoblue.com (11.09.2017)

7. M. Brzezioski, J. Choszowski, J. Homoncik, K. Pierzga, K. Ząber, Z. Ząber, Małe przydomowe elektrownie wiatrowe (ZZ Dr Ząber, 2012)

8. K. Nalepa, W. Miąskowski, P. Pietkiewicz, J. Piechocki, P. Bogacz, Poradnik matej energetyki wiatrowej (WFOŚiGW, Olsztyn, 2011)

9. M. Sathyajith, G. S. Philip, Advances in wind energy conversion technology (Springer, 2011)

10. Stiebler M., Wind energy systems for electric power generation (Springer, 2008)

11. P. L. Fraenkel, Water lifting devices, Wi. Pow. FAO 43, (1986)

12. E. Głodek, Możliwości wykorzystania energii wiatru do wytwarzania energii elektrycznej $w$ województwie opolskim, Wyd. Inst. Śląsk, Opole (2008) 